\title{
Media Culture 2020: Collaborative Teaching and Blended Learning Using Social Media and Cloud-Based Technologies
}

\author{
Richard Vickers \& James Field \\ University of Lincoln, United Kingdom \\ Cai Melakoski \\ Tampere University of Applied Sciences, Finland
}

"The world communications net, the all-involving linkage of electric circuitry, will grow and become more sensitive. It will also develop new modes of feedback so that communication can become dialogue instead of monologue. It will breach the wall between "in" and "out" of school. It will join all people everywhere." McLuhan \& Leonard (1967)

\begin{abstract}
In 2013 five universities from across Europe undertook an innovative project 'Media Culture 2020', combining skills and forces to develop new practices that would face the challenge of the convergence of digital media, taking full advantage of social media and cloud-based technologies. The aim of the Media Culture 2020 project was to demonstrate what $21^{\text {st }}$ century converged and interactive European Media Culture could be in comparison to the broadcasting based one-way 20th century model. The main objective of the project was to break down classroom and campus walls by creating open virtual learning environments where students from different countries and fields could explore and learn together. Media Culture 2020 developed innovative digital learning environments that consider new forms of production, transmission and representation of knowledge. The project utilized a range of online platforms, social media and cloud-based technologies including Facebook, Google+ Google Hangout, Google Docs and Blogger in the collaborative development, management and delivery of the project.
\end{abstract}

Keywords: Media culture; Collaborative teaching; Blended learning; Social Media; Cloudbased technologies

\section{Introduction: Media Culture 2020}

Five universities from across Europe: Tampere University of Applied Sciences (Finland), the University of Lincoln (United Kingdom), the University of Vic (Spain), Liepaja University (Latvia) and HKU Hilversum (Netherlands) made a successful proposal and application for EU funding under the Erasmus Intensive Programme to undertake an ambitious project to develop joint multidisciplinary courses with students and lecturers from the partner institutions. They combined skills and forces to collaboratively develop new course modules and practices that would face the challenge of the convergence of digital media and art, the internationalisation of media production and business, taking full advantage of social media and cloud-based technologies. The Eurovision Song Contest and other contests arranged by European Broadcast 
Union and television formats like Euronews and Eurosport are established broadcast centered Media Culture actors. But where is the European vision of 21st Century Interactive Transmedia and Cross Media for young audiences who are not pleased with reception, but urge to participate and create?

Convergence and Divergence are the megatrends in media culture. Old and new media formats converge but at the same time media consumption is diverging from television and the Internet to smart phones, tablets, public huge interactive screens and multimedia players. Through Social Media, audiences do not merely receive broadcasts, but interact with them and create new content. Where are the European platforms and formats of the new Media Culture Scene? The Media Culture 2020 project aimed to find some answers to this challenge by inviting students and lecturers possessing different knowledge and skills to create mixed media contents, which reflect the richness and diversity of new European Media Culture for various devices.

The Media Culture 2020 project not only offered our students and lecturers an opportunity to work together and learn from each other. It offered us a possibility to create new kinds of learning outcomes and products when blending different ways of story telling and media production in a context where the connected devices and new opportunities are yet to be defined. The most important long-standing objective requiring innovative solutions is in developing online virtual classrooms, studios and labs. Online courses are not a new invention. They are however usually an online replica of traditional teaching in classrooms: one teacher instructing students on one subject involving one field. Among our partners, we have the experience of innovative digital learning environments and the experts that consider new forms of production, transmission and representation of knowledge. This can help us all grow in a changing educational environment where students develop responsibility in an ambiguous and volatile world, and can enhance the life long learning of professors and students.

Our educational purposes, related to the competences, are potential benefits for learners as students like social media as their reference book:

- To offer comprehensive and interrelated knowledge by sharing contents and know-how,

- To educate symbolic analysts, with a less factual and declarative knowledge,

- To give the skills for new forms of production, transmission and representation of contents,

- To prepare on the multiliteracies (other languages not only written),

- To give value to the cultural experiences in the European community space,

- To create a business adventure, feeding a collective space in public.

The ambition was for Media Culture 2020 to develop joint multidisciplinary courses with students and teachers from the five European partner universities. We could also add to the options our students have by opening our own courses to partner university students, establishing virtual student exchange. Our big concern in the present educational situation is this: university budgets are cut down, that can lead to a "one size fits all" education, where students don't really have options to choose from and create a personal professional portfolio. Simultaneously the industry needs individuals with original skills and knowledge sets. If we would offer the selection of our different areas of expertise on a joint tray available for our students, they would have more options to choose from, and study in a truly European atmosphere. 
There were two two-week workshops with 40 students and 10 professors involved: The first workshop was held in Tampere, Finland April 15-27 2013 and the second workshop was in Liepaja, Latvia October 26 - November 8 2013. In addition to the actual mobility, added value was gained by pre- and post workshop activities using social media services, cloud-based technologies such as Google Docs and the free video chat platform Google+ Hangout for meetings and sharing of lectures. These involved even more students and staff members in the project, virtually and without costs for travel and accommodation.

The Media Culture 2020 project presented a unique research opportunity to explore 'blended learning', which Curtis Bonk and Charles Graham (2006: 5) define as a hybrid learning system that combines face-to-face instruction with computer mediated activities. Christopher McMorran (2013) suggests that if used in an educational setting, collaborative technology can enhance active participation (through content creation), increase student engagement, and enrich the learning process. The development of online learning environments alongside established classroom forms must therefore be considered a useful pedagogical approach, since it can serve to facilitate a more collaborative learning experience (Garrison \& Kanuka 2004: 95-105; Berger \& Trexler 200). Collaborative technologies were central to much of the work undertaken throughout this project, thus providing an opportunity to evaluate the educational merits of some of these tools.

\section{Cloud-Based Technologies for Collaborative Development}

The Media Culture 2020 project proposal was written on a Google Docs document, lead by Cai Melakoski at TAMK University of Applied Sciences, Tampere, Finland, with input from the other partners. Dan Greenstein (2013) says that 'for higher education to fulfil its historic role as an engine for social mobility and economic growth, we must continue to seek big technology breakthroughs'. Social media and cloud-based technologies may offer in part, a potential breakthrough. Social Media offers many new platforms for collaborative learning like wikis and blogs. They are easy to use and maintain, the teacher can focus on supporting the students instead of focusing on the maintenance of the platform. According to the creator of the first wiki software, Ward Cunningham (2002), a wiki is "the simplest on-line database that could possibly work." The most popular and well-known wiki is of course Wikipedia. A wiki is used and edited using a common web browser and used collaboratively to create, edit and maintain documents. It is a very good tool for shared knowledge building and learning.

The old way of managing creation of a collaborative document is that the coordinator sends a draft to the team as an email attachment. Then as each person inputs to, or edits the original document, version control can quickly become an issue and finally no one knows who has amended what and there is no final version, just confusion. When collaborative documents are prepared on a wiki, there is only one version, which is always up to date and includes all corrections. Wiki software stores the history of the pages which is also a very useful feature. The coordinator edits the final version and everything is ready for moving forward. There are two main developments that have made use of collaborative online tools possible. The technical reason is that the net is faster, high quality wiki software is available, and more and more people can access the content not only with desktop computers but with different mobile devices. The political reason is the urge of revolution in education; to move from 
teacher centred standardised test oriented education to student centred, learning focused education.

The Media Culture 2020 project offered an opportunity to evaluate the tools and establish processes for collaborative working, as documenting the planning process and providing a shared repository for staff and student contributions before, during and after the workshops in Tampere and Liepaja, was key to the projects success. The lead partner championed Google+ and associated applications (Google Docs and Google Drive) as the core tools for the process. Google+ is a social network that allows you form "circles", ideal then for distinguishing professional groups from purely social groups. Its main strength however is the "Hangout" feature which allows video conference calling for up to 9 participants. What makes Google Hangouts extremely useful and appropriate for this particular task was its ability to integrate Google Docs, screen-sharing and a streamlined 'invitation to join' process. Additionally, a "hangout" can be saved to the YouTube platform for future referencing and even broadcast live. These features were attempted and are discussed later.

Whilst the Google+ social network is by no means sparsely populated (359 million active users as of May 2013: Ward: 2013), it still isn't as widely recognised and utilised as Facebook for social-based communication and rapid discussion instigation. Therefore Facebook was tasked with the "coffee room" function as it became known, an informal, central hub for internal discussions, publications, sharing of information and cultural exchange. In identifying key trends the Executive Summary of the NMC Horizon Report states that:

'Social media, already very well established in the consumer and entertainment sectors, is rapidly integrating into every aspect of university life; with its maximum impact expected to manifest itself within the next year, there is considerable room for creative ideas'. (2014, p 9)

With such a high profile project funded by an external body, the project required a means of disseminating proceedings, events and output via a public-facing medium. For this role a blog was created (Blogger.com) with all lecturers given the capacity to publish content. The curation process of information is what distinguishes the blog from the more informal platform of the social network and although work was published to both, the context was different for each.

The use of 4 tools (Google Docs/Drive, Hangout, Facebook \& Blogger) to aid working collaboratively did however overcomplicate the process on a number of occasions. If you discount for a moment that sharing everything on Facebook allows for certain bridges between content and ideas, the biggest difficulty was locating where everything was especially when there was a structural change to how the documentation was organised. Working in this way was new to most of the participants and we were therefore unable to foresee that the amount of work being produced quickly outgrew our original structure for organising documents. When the inevitable reshuffle happened, links to documents posted on Facebook became broken. The same would have been true even if we opted to use Google+ as the social networking tool. Despite how well the tools were used they still did not fully resolve the realworld issues of remote collaborative working, they certainly made sharing and contributing to planning documentation easier. They were also successful at providing a platform to promote the project formally to interested parties. 


\section{Media Culture 2020: Project Methodology}

The quality of mobilities for the Media Culture 2020 participants were enhanced by online learning with students and teachers working together before and after the workshops in Tampere and Liepaja. These pre- and post-workshop activities were not arranged inside each school, but in multidisciplinary teams with representatives from all partners. The project offered a test bed to innovate and develop a new kind of European mobility using Social Media tools and practices: joint virtual class rooms, labs and studios implementing joint course modules, where each partner gave input with their special skills.

The multidisciplinary approach was clear: TAMK offered expertise in interaction design and educational use of social media; HKU in applied narrative design and software \& hardware development, University of Vic in entrepreneurship, business, audio visual and media production and blended learning, Liepeja University in combining virtual and physical worlds and immersive media, Lincoln University in games design, mobile phone gateway development, user experience design, convergent media practice, emergent media technologies and participative project development. No partner was the sole authority in any of the fields of expertise, but no party could implement this enterprise alone. On a general level, all parties deal with art and media, but with different contents and uses.

In comparison to the courses that already existed in the partner institutions, the added value the Media Culture 2020 project offered were: different design processes related to digital collaborative work, and new approaches to diverse ICT and Social Media learning methods that enhance the educational model for both the student and the lecturer. For the student: improvement of learning self-management; implementation of collaborative work in a European environment; improvement of the quality of the mentoring; diversification of activities and professional abilities. For the lecturer: new pedagogic forms of relationship with students; implementation of blended monitoring and evaluation; diversification of tools for organizing activities related to contents. The result is that both lecturers and students try and learn different traditional and new media elements in innovative ways.

The pedagogical and didactical approaches of this intensive programme are illustrated by the key phrases: competence based learning, collaborative learning, project based learning, problem based learning. The students were BA students in their third or fourth year selected after an open call, with the selection process taking into account the level of English, the interest in mobility, the skills of students in collaborative work and in the use of new technologies. There were a total 10 lecturers and 40 students from the 5 partner institutions. Collaborative online and mobile platforms, social media, ICT tools and cloud-based technologies were used for the learning environment especially before and after the actual workshops in Tampere and Liepaja. David Helfand (2013) considers that contemporary graduates should be:

"skilled in communication, imbued with quantitative reasoning skills, instinctively collaborative, inherently transdisciplinary in their approach to problems, and engaged in their local and global communities-broadly educated individuals with an informed perspective on the problems of the 21st century and the integrative abilities to solve them." 
For the Media Culture 2020 project students worked together online before and after the workshops, news and results were posted to the project blog (which is the web site of the project). Meetings using Google+ Hangout video conferencing were arranged both when preparing the workshops and assessing the results afterwards. All project results are available online via the project blog. As this was a unique project that was dependent on a network of connections between people of varying roles, responsibilities and locations, reflecting on the various mechanics and activities proposed seems logical as even after only a short period of time it became clear that improvements for future, remote, collaborations ventures that used this project as a measure or platform needed to be made.

\section{Student as Producer}

The Media Culture 2020 project also offered the opportunity to explore and embed on a transnational scale, the methodology and aims and objectives of the Student as Producer concept already established at the University of Lincoln:

Conventional models of higher education have seen a schism develop between the two most fundamental activities which take place in universities: teaching and research. At the University of Lincoln, these two activities are not viewed as competing priorities but as integral components of a broader process, which is the real essence of a university: the creation of knowledge and meaning.

The core concept of the Student as Producer project, led by the Educational Development and Enhancement Unit (EDEU) at the University of Lincoln, is research-engaged teaching. This means encouraging students at all levels and across all disciplines to see themselves as active producers of knowledge, rather than passive consumers. The principle of research-engaged teaching now underpins the curriculum across all subject areas at the University of Lincoln.

The project emphasises the role of students as collaborators. Undergraduates are given opportunities to work with academics, postgraduates and support staff on real academic research. In this way students become part of the academic project of the University and make a meaningful contribution to the production of knowledge alongside experienced researchers. Through practice and primary engagement with research, students extend and improve their practical and academic skills, which in turn increases their employment prospects and opportunities to pursue further study.

Discovery: The open-ended brief and flexible teaching structure empowered students to define the working environment. The structure of the workshop itself was open to negotiation, whilst students were encouraged to pool their collective research and practice skills. This approach was designed to engage students in the discovery and sharing of new knowledge by underscoring the importance of research within the conceptual development stage.

Technology in Teaching: Media Culture 2020 utilised a range of Google Drive and associated software (Docs, Presentation and Hangouts) to share information. The project also made use of a blog to publicise the project, as well as a number of social media platforms to foster closer working partnerships between staff and students. We believe that by leveraging the capabilities of Web 2.0 technologies this model of digital scholarship can facilitate a more open, interactive and collaborative working environment for teaching and learning. 
Space \& Spatiality: The technologies and virtual learning environments used in this project allowed for real-time collaboration whereby information and knowledge could be accessed and disseminated across a number of networked devices.

Student Voice: The established teacher/student divide was avoided wherever possible, with optional seminars, interactive workshops, student-led presentations, group discussions and plenaries taking the place of the traditional, rigid lecture/seminar structure.

Research \& Evaluation: Participants were engaged in active research activities throughout the conceptual development, presentation and delivery of projects. A collaborative approach to research was encouraged, with both staff and students contributing to an archive of research sources. A number of open plenaries were held to discuss and evaluate this research in relation to developing student concepts.

\section{Pre-workshop Phases}

Six weeks before the workshops the introduction of participants, team building and teamwork started using online social media tools. At least one student from each partner institute was in each of the five teams with one lecturer per team as the main coach. The idea of the preworkshop phase of activities in theory was a good one because it could engage students in their local groups and their international groups and could also act as an icebreaker for when the students were together. In the case of MC2020, this practice yielded some success. Whilst some activities struggled to attract engagement from the participants others exceeded expectation and their success suggest a model of collaborative remote working could be created based on the approach taken and the actual content of the activity.

An example of a task where high user participation was observed was the 'creation of an identity' to visually represent the collective work undertaken as part of the project. Using Google Documents in this manner allowed for qualitative evidence to be gathered and immediate feedback issued and responded to - in some instances; in real-time thanks to the "live" document model where multiple collaborators contribute to the same document and can see when others are viewing and editing it. This in turn allowed for the document to form a social hub around it so ideas were quickly discussed, agreed and documented.

Where tasks were less successful it was observed that the students were possibly uncomfortable with the fact they are working on potentially "live" documents and wished their contributions to be in more finalised or formal state before contributing. This was especially evident with students for whose primary language was not English. On a number of occasions, even on visually oriented activities, it was observed that students would view the documents often but contribute infrequently, if at all. This suggests a willingness to collaborate but there are still apparent barriers that prevent full-engagement that are nothing to do with technology.

For non-real-time collaborations the provisions of Google Drive and Documents worked as intended. Technology is at an accessible juncture for everyone to have a consistent and seamless experience contributing to tasks. However, as with the organisation of this project, activities that did require real-time collaboration proved difficult. Again this can somewhat be 
attributed to the fact that it is very difficult to assemble groups from multiple locations, time zones and schedules to be together and online at the same time.

An example of real-time communication came in the form of shared lectures. Each partner was to host a lecture focusing on a topic that will be relevant to the themes of the project and the idea was to stream them live to the other partners. However the culpable component responsible for the difficulties in engaging on this occasion was the technology itself. Live streaming of these lectures did work to some degree but due to the essential supporting visual content of some presentations, viewing them after compression and decompression for network transmission failed to communicate some of the ideas presented for discussion.

\section{Workshop Phases}

With Digital Media at the very heart of the theme for Media Culture 2020 it was only appropriate for technology to continue playing a vital role regarding collaboration during the phase of the workshops in Tampere and Liepaja. After an initial task to complete outstanding pre-workshop group assignments, the main task was set, only this time, instead of being explicitly asked to use Google Docs, the students were observed creating Google Docs documents to share information, research sources, ideas and in some instances, even used them as replacements to word-processing software despite having such a facilities at their disposal.

The main task was for each student group to prepare concepts demonstrating how technology will impact on or improve a shared European media culture in the year 2020. When considering their responses, students were free to use any existing platform or create one entirely from scratch. The assignment was for each student team to design two concepts for the platforms/channels a-e or a combination of them. (Two concepts: it could be one concept but applied for two different channels/platforms, or two different concepts)

The channels/platforms:

a) Mobile/Service

b) Ubiquitous/Immersive

c) Moving image/Narrative

d) Game/Interactive

e) Media Art

f) Transmedia

e) Online community (next level social media)

Themes/topics:

Team 1- Online communities, offline impact

Team 2- Hyperreal - hyperfake

Team 3- Nonnarrativity is the new 'storytelling'

Team 4- Connecting culture's

Team 5- The power (and challenges) of shared knowledge

Most concepts appeared to be based on the familiar platform of apps that either launched from an existing mobile smart device or some device currently in development suggesting that students do not sense any seismic shift in the way we interact technology within the next 7 
years but some looked further ahead to technology that is theoretical but has not yet been put into production allowing them total freedom when deciding interaction models and content, something that was encouraged by the project. The blend of both synchronous and asynchronous teaching methods fostered an open, blended learning environment, one that extended the traditional boundaries of the classroom in time and space. The interactive and decentralized nature of these digital tools enabled staff and students to communicate and strengthen social ties, alongside participation in the production of new knowledge and media content. These services were also important for embedding the skills and knowledge delivered throughout the workshop phase.

Ownership of intellectual property is an issue students tend to worry about and there were questions raised during the workshop of who exactly owns the work produced for this project. This illustrates a potential setback for collaborative work in general and can maybe highlight another reason why some of the tasks in the pre-workshop phase were not as engaged with as was expected. There was a eureka moment for some students when they realised the potential the concept of shared ownership provided and was soon something they were then observed embracing, primarily due to the shift in role of their co-collaborators. Whereas during the pre-workshop they were known only as strangers with a digital footprint, after meeting, sharing real-life experiences and cultural exchanges with, they were now seen as friends and colleagues. In terms of collaborative working and the technology available to participants, this particular phase was a complete success because the aforementioned barriers of remote working were no longer an issue and technology was able to be used as it was intended, and as ever, the non real-time communication platforms continued to provide an appropriate toolset to document and share progress and experiences. It was also observed extending beyond just providing a set of tools; it became a catalyst to change perceptions of trust.

In addition to the intensive workshop, cloud-based and social media tools were used to extend the methods of teaching and learning within an open, virtual learning environment. This mode of 'blended learning' was designed to enhance the learning experiences of a diverse set of students from different disciplinary contexts. Google+ and associated applications (Google Docs, Google Drive and Google Hangout) were implemented as the core tools for this process. Google Docs was utilized due to the range of integrated software needs it fulfils (word processing, spread sheets, presentations, etc.). This platform enabled all participants to easily create and share documents from within the web browser, which could be accessed by a range of networked devices. The associated 'cloud' storage service, Google Drive, allowed these documents to be shared to all participants instantaneously, whilst also facilitating a separate space for admin purposes. Throughout the project student groups each had their own folders for sharing work in progress, which the lecturers could also see and comment on if required.

In their summative evaluation of the Tampere workshop from the University of Vic considered that the experience has been very enriching due to the diversity background of students and the challenging goals we had. As professors we consider it was a major opportunity to start a new way of teaching-learning process in a European context. The collaborative work between coordinators, lecturers and managers has proved it is possible to work in a big inter-university team. We had a good reaction at our University in both students and professors concern about a different way to conceive the new University we wish to have: more opened, able to respond to the constantly society's demands, capable to make linkages and networks allowing the flow of knowledge and innovations. From UVIC's perspective we have to say that the impact of 
Media Culture 2020 has been strongly positive, promoting a self-criticism debate about the need to change and to look for new imaginative ways to work.

The students referred to MC 2020 as: "it was the best experience ever as students", or "it was a life experience!". Their feedback generated a "me too" desire atmosphere to participate. The high-level of collaborative work achieved was unique. The results were amazing, even the short time to develop concepts. The heterogeneous base of knowledge and culture of the students gave them an opportunity to learn fast and quick, to debate and improve ideas day by day, and to be more creative due to the different approaches. The two students from the business field were amazed by the successful educational methodology. To work with people from different countries gives to the project an added value because cross-country teams with cultural differences and backgrounds has increased the project attractiveness due to the different perspectives that can appear. (Media Culture 2020 blog)

\section{Conclusion}

For the students and lecturers from the 5 partner institutions taking part in Media Culture 2020, social media platforms offered an innovative solution to learning and teaching in a collaborative manner. Facilitating the 6 -weeks of pre-workshop activities prior to the workshops, documenting the process during the workshop and provide channels for dissemination after. These platforms offer excellent opportunities and models of working for non-real-time collaborations, but there are still issues with real-time logistics for arranging different groups of people to present simultaneously. The wiki, the blog and the European Media Culture demos will continue to be accessible online. Facebook was the meeting 'room' prior to the events in Tampere, and Liepaja, and has proven to be a great way of everyone keeping in touch since they returned to their respective countries.

The Media Culture 2020 project was considered to be a great success by all the partners, academics and especially the students who took part. It is a true example of an intercultural, multidisciplinary, blended learning experience in higher education that achieved it goals of breaking down classroom walls and bridging geographical distance and cultural barriers. The students with different skills, coming from different countries and cultures, interacting with other enlarges the possibilities of creativity, collaboration and quality work. The fact that the intensity of the programme in such a short period of time was a big challenge for the students' incentive, and in future editions we would therefore rather concentrate on further development of the intercultural concept thinking and on a stronger relation of conceptual achievements in combination with the creation of business plans. A stronger relation with the professional world can be sought. We suggest a next edition's slogan: Solve a future problem in real life with a design and then set yourself a deadline. Maybe it's better for each team to have a problem to work on instead of a given subject.

The blend of both synchronous and asynchronous teaching methods fostered an open, blended learning environment, one that extended the traditional boundaries of the classroom in time and space. The interactive and decentralized nature of digital tools enabled staff and students to communicate and strengthen social ties, alongside participation in the production of new knowledge and media content. For students and lecturers, the implementation of social media and cloud platforms offered an innovative solution to both teaching and learning in a collaborative manner. By leveraging the interactive and decentralised capabilities of a 
range of technologies in an educational context, this model of digital scholarship facilitates an open and dynamic working environment. Blended teaching methods allow for expansive collaboration, whereby information and knowledge can be accessed and disseminated across a number of networked devices.

\section{Acknowledgements}

Cai Melakoski, Lenno Verhoog, Rosa Pons, James Field, Anna Trapenciere, Cyrille Bloemers, Andris Vētra, Alejandra Aramayo, Graham Cooper, Martyn Thayne \& Richard Vickers.

\section{Online Material}

\section{Project Bog}

The Media Culture 2020 Blog documents the project, the pre-workshop activities and the workshops in Tampere and Liepaja. The blog is the public interface of the project, inviting everybody interested in the topics of the project to contribute with their opinions and insight with comments on the blog. [http://mediaculture2020.blogspot.co.uk/]

\section{Videos}

A video documenting the Media Culture 2020 Tampere, Finland workshop is available to view online. The film was produced by the HKU student team Oavsett (Hugo de Kok, Kay van Vree \& Edwin Haverkamp) and the logo is designed by Yonatan Wolowelsky. [http://vimeo.com/66458056]

A video documenting the Media Culture 2020 Liepaja, Latvia workshop is available to view online. The film was produced by the HKU student team 'The Cake Takers' (Bas ten Berge, Robin Bosman \& Tom Polkamp). [https://www.youtube.com/watch?v=fAVrq4aOHQM]

\section{References}

Berger, P. \& Trexler, S. (2010). choosing Web 2.0 tools for learning and teaching in a digital world. California: ABC-CLIO.

Bonk, C.J. \& Graham, C.R. (2006). The handbook of blended learning environments: Global perspectives, local designs. San Francisco: Jossey-Bass/Pfeiffer.

Cunningham, W. (2002). What is a Wiki? Retrieved on 9 February 2013 from http://www.wiki. org/wiki.cgi?WhatlsWiki

Doctor, V. (2012). Is social media good for education? Retrieve on 9 February 2013 from http://www.hashtags.org/platforms/twitter/is-social-media-good-for-education

Fuchs, C. (2014). Social media: A critical introduction. London: Sage.

Garrison, D. R. \& Kanuka, H. (2004). Blended learning: Uncovering its transformative potential in higher education. The Internet and Higher Education, 7, 95-105 
Greenstein, D. (2013). Change is coming. Retrieved on 9 February 2013 from http://www.insidehighered.com/views/2013/12/16/essay-arguing-major-changes-arecoming-higher-education

Helfand, D.J. (2013). Watering the roots of knowledge through collaborative learning. Retrieved on 9 February 2013 from http://chronicle.com/article/Watering-the-Rootsof/140135/

Hinton, S. \& Hjorth, L. (2013). Understanding social media. London: Sage.

Johnson, L., Adams-Becker, S., Estrada, V., \& Freeman, A. (2014). NMC Horizon Report: 2014 Higher Education Edition. Austin, Texas: The New Media Consortium.

McLuhan, M. \& Leonard, G.B. (1967, Feb. 21). The Future of education: The Class of 1989. LOOK Magazine, 23-25.

McMorran, C. (2013). Collaborative learning using Google docs and maps. Technology in Pedagogy, 15, 1-8.

Mandiberg, M. (Ed.). (2012). The Social media reader. New York. New York University Press.

Media Culture 2020. (2013). Project blog. Retrieved on 27 March 2014 from http://mediaculture2020. blogspot.co.uk/

Seaman, J. \& Tinti-Kane, H. (2013). Social media for teaching \& learning. Boston. Pearson Learning Solutions.

University of Lincoln. (2014). Student as producer. [Online]. https://www.lincoln.ac.uk/ home/studyatlincoln/undergraduatecourses/discoverlincoln/teachingandlearning/stude ntasproducer/

Watkins, T. (2013) Suddenly, Google Plus is outpacing Twitter to become the world's second largest social network. Retrieved on 9 February 2013 from http://www.businessinsider. com/google-plus-is-outpacing-twitter-2013-5

Correspondence: Richard Vickers, Deputy Head, Lincoln School of Film and Media, University of Lincoln, Brayford Pool, Lincoln, United Kingdom 